\title{
Prevalence of Bipartite Patella in Turkish Population. Analysis of Bilateral Knee Radiographs in 897 Subjects
}

\author{
Prevalencia de Patela Bipartita en una Población Turca. \\ Análisis de Radiografías Bilaterales de Rodilla en 897 Sujetos
}

\author{
Ozkan Kose*; Ali Eraslan**; Ali Ergun*; Omer Faruk Egerci* \& Emrah Cevat Ercan*
}

KOSE, O.; ERASLAN, A.; ERGUN, A.; EGERCI, O. F. \& ERCAN, E. C. Prevalence of bipartite patella in Turkish population; analysis of bilateral knee radiographs in 897 subjects. Int. J. Morphol., 33(3):1108-1113, 2015.

SUMMARY: Bipartite patella is a normal anatomic variant of patella. There are various data about the prevalence of bipartite patella in the literature. The aim of this study was to investigate its prevalence, type distribution and sex predilection in Turkish population. Bilateral knee radiographs were retrospectively reviewed of 897 consecutive adult patients. Cases with bipartite patella were categorized according to the Oohashi classification. Medical records were examined in order to differentiate symptomatic and asymptomatic bipartite patellae. We contacted symptomatic patients by telephone to learn continuity of knee pain. We identified 11 cases ( 7 male, 4 female) of bipartite patella among the 283 male and 614 female patients. No bilateral cases were identified. The prevalence of bipartite patella was $1.22 \%$ overall, $2.47 \%$ in males, and $0.65 \%$ in females. The most common type was superolateral bipartite patella as seen in 9 patients $(81.8 \%)$. One subject had lateral bipartite and one subject had superolateral tripartite patella. Painful bipartite patella was found in only 2 patients (18\%). One of them had continuing symptoms even after 12 months. In conclusion, we found that the prevalence of bipartite patella in Turkish population was approximately $1 \%$. Both inclusion of only adult (skeletally mature) subjects and assessment with bilateral imaging increased the reliability of this value. In accordance with the literature, bipartite patella was found significantly more frequent in males and mostly in superolateral type. More studies are needed in order to obtain the prevalence, type and sex distribution of bipartite patella in different populations.

KEY WORDS: Bipartite patella; Turkish population; Prevalence; Epidemiology.

\section{INTRODUCTION}

The patella is the largest sesamoid bone in the human body. It generally develops from a single ossification nucleus, and ossification starts from center towards periphery. The primary ossification nucleus appears between 3 to 5 years of age. During the ossification of patella, secondary ossification centers may appear around 12 years of age (Ogden, 1984). Complete fusion of primary and secondary ossification centers causes formation of a unique patella. However, bipartite or tripartite patella forms occur when these ossification centers fail to fuse and remain separate. Bipartite patella (BP) is accepted as a normal anatomic variant of patella, and usually remains asymptomatic and identified incidentally on knee radiographs taken for other reasons.

BP was first described in German literature (Gruber, 1883). Approximately forty years later, Saupe (1921) proposed the first classification system for BP by analyzing some cases reported in the literature. This classification system is based only on the location of the fragment and BP is grouped into three distinct types (Fig. 1). Most recently, Oohashi et al. (2010) reclassified the BP and proposed a new classification system which is based on both location and number of fragments (Fig. 2). They claimed that there is no true secondary ossification center at the inferior pole of patella and previously reported inferior pole BP (Saupe classification Type I) was actually sequel of Sinding-LarsenJohansson disease (traction apophysitis of inferior patellar pole). Therefore, they excluded inferior pole BP from classification, and included two other subtypes composed of more than two fragments (tripartite patella).

The true prevalence of BP is difficult to determine due to the high rate of asymptomatic subjects. A few number of studies investigated prevalence of BP in the literature. However, these studies reported very variable prevalence of

\footnotetext{
* Antalya Education and Research Hospital, Orthopedics and Traumatology Department, Antalya, Turkey.

** Antalya Education and Research Hospital, Sports Medicine Department, Antalya, Turkey.
} 
$\mathrm{BP}$ and some of them reviewed only single knee of a subject (either right or left). The purpose of this study was to examine the plain anteroposterior and lateral radiographs of the knees in Turkish subjects in order to determine the prevalence of BP and analyze the differences between sex and laterality.

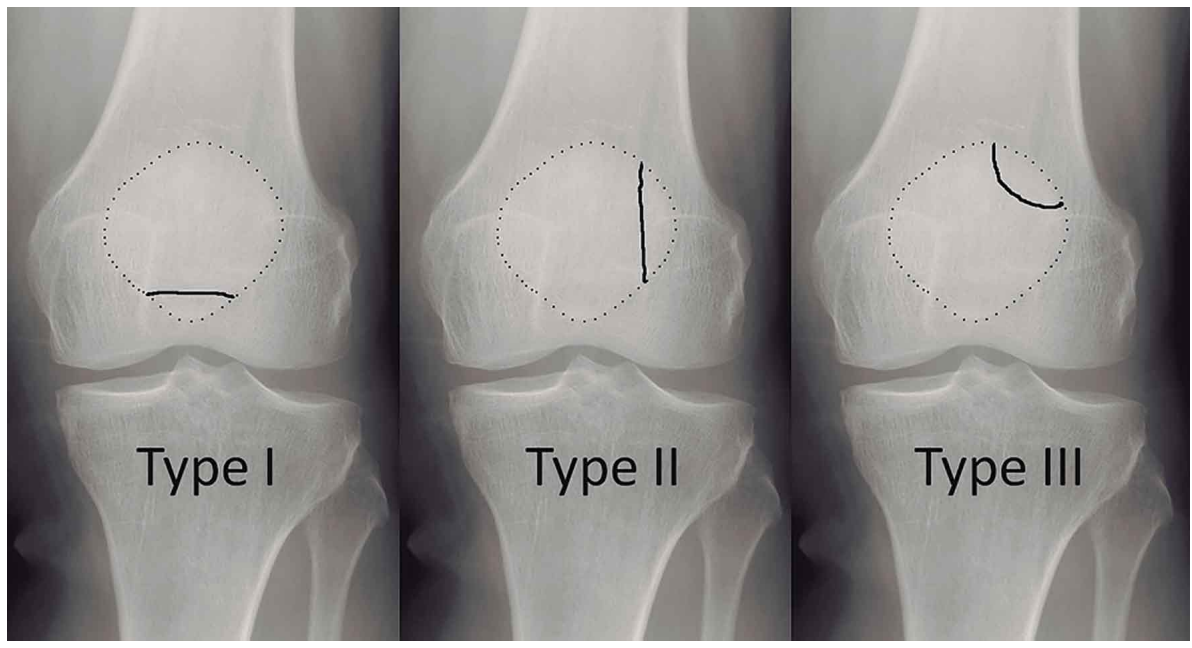

Fig. 1. Bipartite patella classification described by Saupe (1921).

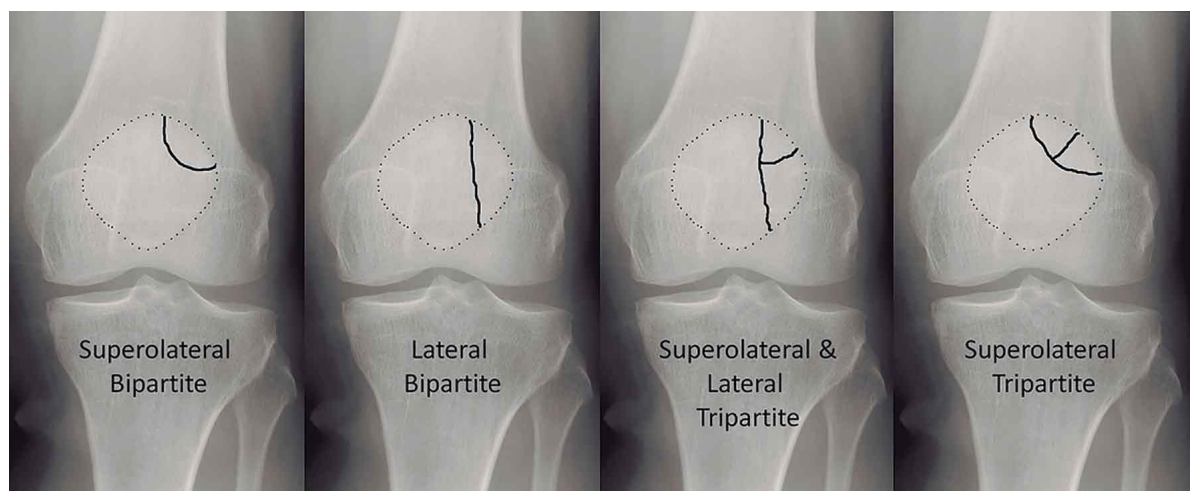

Fig. 2. A new classification described by Oohashi et al. (2010).

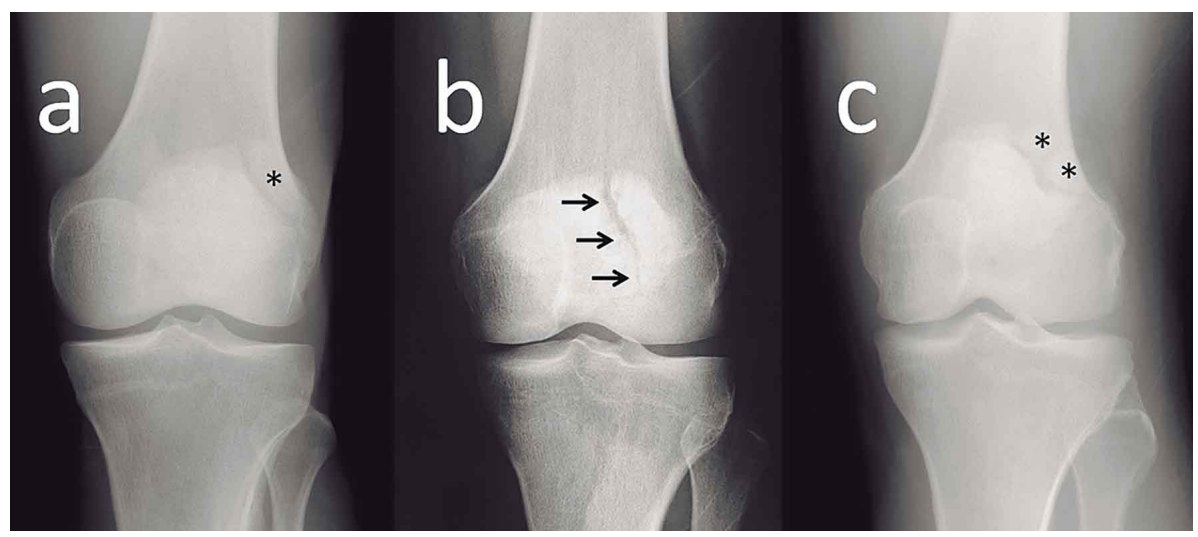

Fig. 3. Radiographies of 24 years-old female (a, superolateral bipartite patella), 34 years-old male (b, lateral bipartite patella) and 57 years-old male (c, superolateral tripartite patella) patients.

\section{MATERIAL AND METHOD}

We retrospectively reviewed consecutive adult patients of whom bilateral knee radiographs were taken between January 2014 and June 2014 for all indications from picture archiving and communication systems (PACS) and institutional clinical database. We excluded 45 patients, in which the patella was not clearly depicted due to incorrect patient positioning, making it impossible to judge about the presence of a BP. Finally, bilateral antero-posterior and lateral knee radiographs of 897 patients (1794 knee radiographs) were eligible and included in this study. The study was carried out according to the principles of the Declaration of Helsinki.

Initially, two orthopedic surgeons reviewed all radiographs and searched for segmented patella in typical locations independently. Later, a final decision was reached with consensus on uncertain cases. Oohashi et al. classification was used to classify the type of BP (Fig. 2). The archive records of patients with BP were scanned to determine whether there was a relationship between knee pain and BP. Then, patients with painful BP were contacted by telephone and a questionnaire about the continuity of pain was recorded. No detailed statistical analysis was performed in this study. The continuous variables were presented as means and standard deviations, and categorical variables were presented as frequency distributions and percentage. 


\section{RESULTS}

Of the 897 patients, 283 were male and 614 female. The mean age of the entire group was $40.9 \pm 14.8$ years (range of $18-79$ years). We identified 11 cases of BP in 11 patients (mean age $40.4 \pm 12.7$ years, range of $24-62$ years). No bilateral cases were identified. 7 (63.6\%) were male and $4(36.4 \%)$ were female of these patients. The prevalence of BP in male patients was $2.47 \%$ (7/283), and $0.65 \%$ (4/ $614)$ in female patients, and overall $1.22 \%$ (11/897). The most common localization was superolateral margin of the BP as seen in $81.8 \%$ (9/11) patients. There were one subject with lateral bipartite and one subject with superolateral tripartite patella (Fig. 3). BP was found at the right knee in $6(54.5 \%)$, at the left knee in $5(45.5 \%)$ subjects.

Among the 11 patients, BP was incidentally found in radiographies of 9 patients with another knee disorder, while it was held responsible for symptoms in 2 patients (18\%). They were 26 and 28 year-old males, and had been treated conservatively. Telephone contact with these two patients revealed that only one of them (26 years-old) had continuing complaints related to BP after 12 months. This patient was an active person. Local pain immediately after strenuous activities was his major symptom. Table I summarizes the demographic characteristics of patients with BP.

Table I. List of BP cases and their clinical and radiologic characteristics.

\begin{tabular}{lccccc}
\hline Case \# & Age & Sex & Side & Localization and type & Symptoms \\
\hline 1 & 47 & Male & Right & Superolateral, Bipartite & None \\
2 & 34 & Female & Right & Superolateral, Bipartite & None \\
3 & 39 & Female & Right & Superolateral, Bipartite & None \\
4 & 26 & Male & Right & Superolateral, Bipartite & Symptomatic \\
5 & 62 & Male & Left & Superolateral, Bipartite & None \\
6 & 24 & Female & Left & Superolateral, Bipartite & None \\
7 & 57 & Male & Left & Superolateral, Tripartite & None \\
8 & 51 & Female & Right & Superolateral, Bipartite & None \\
9 & 28 & Male & Left & Superolateral, Bipartite & Symptomatic \\
10 & 43 & Male & Right & Superolateral, Bipartite & None \\
11 & 34 & Male & Left & Lateral, Bipartite & None \\
\hline
\end{tabular}

\section{DISCUSSION}

In the literature, there is wide variation in the prevalence of BP in different ethnic groups. Some archaeological studies that had been conducted on various geographical areas revealed some prevalences such as 6.7\% (Mullen \& Hoppa, 1992), 8.0\% (Anderson, 1964), 15.3\% (L'abbe et al., 2008). These high figures may be due to familial relationship between found bones. 682 skeletons were analyzed in a cadaver study, and a 3\% prevalence of BP was found with male dominancy (Todd \& McCally, 1921). Green (1975) claimed that the prevalence was ranging from $0.2 \%$ to $6 \%$. In the German literature, reported prevalence values were $0.05 \%$ (Stucke, 1950), 0.20\% (Paas, 1931), 1.54\% (Siemens, 1931), 1.66\% (Blumensaat, 1933).

We found that the prevalence of BP in Turkish population was 1.22\%. "The imaging studies" related to prevalence of BP in the English literature were searched and presented in a detailed table (Table II) for comparison (Aydınloglu et al., 1997; Johnson et al., 1998; Kavanagh et al., 2007; Matrawy et al., 2014; Snoeckx et al., 2008). We used direct radiography instead of MRI in the retrospective scan. Because bilateral evaluation is practically not possible with MRI and the contralateral knee without the MRI results might have an asymptomatic BP. This is the reason why prevalence values reported with MRI studies (Kavanagh et al.; Matrawy et al.; Snoeckx et al., 2008) are thought to actually be higher. It is clear that the imaging method might affect the prevalence value.

Age is another factor influencing the prevalence. We did not include children or adolescents in the study. Since in those individuals, it cannot be predicted during developmental process whether accessory ossification center(s) will show complete fusion with main patellar nucleus or will remain as unfused part(s). That's why we only included adult patients over 18 years-old in order to avoid false positive results. However, under 18 year-old subjects were either included in the population or counted as BP case by some researchers (Aydınlıoglu et al.; Kavanagh et al.; Matrawy et al.) (Table II). The first one decreases the prevalence, while the latter increases.

Determining the true prevalence of BP is difficult due to the high rate of asymptomatic subjects, so BP is usually detected incidentally. Since a retrospective study is obtained from patients' records, it can be considered that the symptomatic BP cases more participate in the study population. Therefore, a prospective and crosssectional study designed to scan a large population will provide more 
correct prevalence. Most of the BP cases $(82 \%)$ were asymptomatic in our study. To correct our prevalence value, 2 symptomatic patients can be excluded from the calculation. A prevalence of $1.0 \%$ arises when 9 (11-2) asymptomatic BP cases recalculated with 895 (897-2) patients. It seems that the results of other bilateral roentgenographic studies (Aydınlıglu et al.; Johnson et al.) are closer to our prevalence (Table II). In this manner, the mean prevalence of BP can be thought as around $1 \%$.

Green (1975) reported that BP is seen 9 times more in males than females. Other studies showed male/female rate of 2.1 (O'Brien et al., 2011), 3.1 (Kavanagh et al.), 3.3 (Ogata, 1994), 3.4 (Oohashi et al.) and 4.3 (Weaver, 1977). But these are not the prevalence rates obtained by population scanning, only the ratio of the number of BP cases. In our study, even though most of the patients scanned in retrospect were female, cases with diagnosed BP were mostly males. Thus, the rate of male prevalence $(2.47 \%)$ to female prevalence $(0.65 \%)$ was found to be 3.8 . With this result, the fact that BP is significantly seen more often in males was again proved to be true with our study.

In previous studies, bilateral BP's diagnosis rates were reported in various percentages such as 25\% (Oohashi et al.), 43\% (Weaver), 50\% (Green), 56\% (O'Brien et al.). Unilaterality of all 11 cases in our study was not in accordance with the literature. Still, the most common case type was superolateral type $(81.8 \%)$ as in previous studies. The rarely seen tripartite patella was found in 1 and lateral BP was found in 1 case.

Symptomatic cases are usually adolescents and young adults with anterior knee pain as the main complaint (Green; Ishikawa et al., 1994; Ogata; Oohashi et al.; Weaver). That is why differential diagnosis in anterior knee pain should include $\mathrm{BP}$ as well as other reasons. As our symptomatic case, BP usually becomes symptomatic after strenuous physical activity which includes vastus lateralis abnormal pulling or abnormal movement of synchondrosis as a result of sudden trauma. In symptomatic cases, MRI imaging studies can be used to determine the relationship between main patellar nucleus and fragments or bone edema presence in detail (Kavanagh et al.; Matrawy et al.; Snoeckx et al.). Skyline radiography taken in squatting position can be added to 2-directional radiography for easier identification of painful BP (Ishikawa et al.).

In treatment of painful BP, conservative methods such as restriction of movement, NSAIDs, patellar braces, ultrasound, quadriceps stretching exercises and local steroid injections are used first (Atesok et al., 2008; Gaheer et al., 2009). The most common surgical approach today is excision of the painful fragment. Lateral retinacular release, vastus lateralis release, subperiosteal detachment of vastus lateralis insertion and open reduction-internal fixation (ORIF) are other surgical options (Atesok et al.; Gaheer et al.). 
In differential diagnosis, patella fractures (traumatic or stress) should be considered primarily (Brown et al., 2015). Symptomatic BP cases may be misdiagnosed as patella fractures, or vice versa. Also, patella tumors should not be overlooked in differential diagnosis (Mercuri \& Casadei, 2001). Last, gout disease and patella dorsal defects can also accompany BP (Kobayashi et al., 2005; Mellado et al., 2001).

\section{CONCLUSION}

This study investigated the prevalence of BP in Turkish population, and we found it around $1 \%$. This value was obtained from only skeletally mature subjects with bilateral imaging. Therefore, we think that this is a reliable value. In accordance with the literature, BP was found more frequently in males and mostly in superolateral type. More clinical trials are necessary in order to determine the prevalence, sex and type distribution of BP in other populations. Further studies should be prospective crosssectional, and use bilateral radiography on a large population over 18 years-old.

KOSE, O.; ERASLAN, A.; ERGUN, A.; EGERCI, O. F. \& ERCAN, E. C. Prevalencia de patela bipartita en una población Turca; análisis de radiografías bilaterales de rodilla en 897 sujetos. Int. J. Morphol., 33(3):1108-1113, 2015 .

RESUMEN: La patela bipartita es una variante anatómica normal. En la literaturahay varios datos sobre la prevalencia de patela bipartitae. El objetivo de este estudio fue investigar la prevalencia, distribución y aparición según sexo en la población turca. Se revisaron retrospectivamente radiografías bilaterales de rodilla de 897 pacientes adultos. Los casos con patela bipartita se clasificaron de acuerdo a la clasificación de Oohashi. Fueron examinados los registros médicos de los pacientes con el fin de diferenciar los casos de patela bipartita sintomática y asintomática. Se estableció contacto con los casos sintomáticos por teléfono para conocer la continuidad del dolor de rodilla. Se identificaron 11 casos (7 varones, 4 mujeres) de patela bipartita entre 283 hombres y 614 pacientes de sexo femenino. No se identificaron casos bilaterales. La prevalencia de patela bipartita fue de 1,22\% en total, $2,47 \%$ en varones y $0,65 \%$ en las mujeres. El tipo más común fue la patela bipartita superolateral en 9 pacientes $(81,8 \%)$. Un sujeto presentó patela bipartita lateral y en otro caso, patela tripartita superolateral. La patela bipartita dolorosa fue encontrada en sólo 2 pacientes (18\%).
Uno de ellos presentó síntomas que continuaron incluso después de 12 meses. En conclusión, se encontró que la prevalencia de la patela bipartita en la población turca fue de aproximadamente un 1\%. La inclusión en esta investigación de solo sujetos adultos (con el esqueleto maduro) y el estudio de imágenes bilaterales aumentó la fiabilidad de estos parámetros. De acuerdo con la literatura, la patela bipartita se encontró significativamente de manera más frecuente en hombres y en su mayoría se trató del tipo superolateral. Se necesitan más estudios para obtener la prevalencia, tipo y distribución por sexo de la patela bipartita en diferentes poblaciones.

PAlabras ClaVE: Patela bipartita; Población Turca; Prevalencia; Epidemiología.

\section{REFERENCES}

Anderson, J. E. The people of Fairty: An osteological analysis of an Iroquois ossuary. Ottawa, National Museum of Canada Bulletin 193, 1964. pp.28-129.

Atesok, K.; Doral, M. N.; Lowe, J. \& Finsterbush, A. Symptomatic bipartite patella: treatment alternatives. J. Am. Acad. Orthop. Surg., 16(8):455-61, 2008.

Aydınlıglu, A.; Tosun, N.; Arslan, H.; Akpınar, F.; Dogan, A. \& Alıs, T. Aksesuar Patella (Patella bipartita). Ulusal Travma Dergisi, 3(3):200-6, 1997.

Blumensaat, C. Patella partita-Traumatische SpaltpatellaPatellarfraktur. Arch. Orthop. Unf. Chir., 32(1):263-82, 1933.

Brown, G. A.; Stringer, M. R. \& Arendt, E. A. Stress Fractures of the Patella. In: Miller, T. L. \& Kaeding, C. C. (Eds.). Stress Fractures in Athletes. Diagnosis and Management. Heidelberg, Springer International Publishing, 2015. pp.125-35.

Gaheer, R. S.; Kapoor, S. \& Rysavy, M. Contemporary management of symptomatic bipartite patella. Orthopedics, 32(11):843-9, 2009.

Green, W. T. Jr. Painful bipartite patellae. A report of three cases. Clin. Orthop. Relat. Res., (110):197-200, 1975.

Gruber, W. In Bildungsanomalien mit Bildungshemmung begründete Bipartition beider Patellae eines jungen Subjects. Arch. Pathol. Anat. Physiol. Klin. Med., 94:358-61, 1883.

Ishikawa, H.; Sakurai, A.; Hirata, S.; Ohno, O.; Kita, K.; Sato, T. \& Kashiwagi, D. Painful bipartite patella in young athletes. The diagnostic value of skyline views taken in squatting position and the results of surgical excision. Clin. Orthop. Relat. Res., (305):223-8, 1994. 
KOSE, O.; ERASLAN, A.; ERGUN, A.; EGERCI, O. F. \& ERCAN, E. C. Prevalence of bipartite patella in Turkish population; analysis of bilateral knee radiographs in 897 subjects. Int. J. Morphol., 33(3):1108-1113, 2015.

Johnson, L. L.; van Dyk, G. E.; Green, J. R. 3rd.; Pittsley, A. W.; Bays, B.; Gully, S. M. \& Phillips, J. M. Clinical assessment of asymptomatic knees: comparison of men and women. Arthroscopy, 14(4):347-59, 1998.

Kavanagh, E. C.; Zoga, A.; Omar, I.; Ford, S.; Schweitzer, M. \& Eustace, S. MRI findings in bipartite patella. Skeletal Radiol., 36(3):209-14, 2007.

Kobayashi, K.; Deie, M.; Okuhara, A.; Adachi, N.; Yasumoto, M. \& Ochi, M. Tophaceous gout in the bipartite patella with intraosseous and intra-articular lesions: a case report. J. Orthop. Surg. (Hong Kong), 13(2):199-202, 2005.

L'Abbé, E. N.; Coetzee, F. P. \& Loots, M. A description of iron age skeletons from the Pilanesberg National Park, South Africa. $S$. Afr. Archaeol. Bull., 63(187):28-36, 2008.

Matrawy, K. A.; El-Nekeidy, A. A. \& Al-Dawody, A. MRI features of some uncommon causes of painful knee. Alex. J. Med., $50(2): 149-57,2014$.

Mellado, J. M.; Salvadó, E.; Ramos, A.; Camins, A. \& Saurí, A. Dorsal defect on a multi-partite patella: imaging findings. Eur. Radiol., 11(7):1136-9, 2001.

Mercuri, M. \& Casadei, R. Patellar tumors. Clin. Orthop. Relat. Res., (389):35-46, 2001.

Mullen, G. J. \& Hoppa, R. D. Rogers Ossuary (AgHb-131): An early Ontario iroquois burial feature from Brantford township. Can. J. Archaeol., 16:32-47, 1992.

O'Brien, J.; Murphy, C.; Halpenny, D.; McNeill, G. \& Torreggiani, W. C. Magnetic resonance imaging features of asymptomatic bipartite patella. Eur. J. Radiol., 78(3):425-9, 2011.

Ogata, K. Painful bipartite patella. A new approach to operative treatment. J. Bone Joint Surg. Am., 76(4):573-8, 1994.

Ogden, J. A. Radiology of postnatal skeletal development. X. Patella and tibial tuberosity. Skeletal Radiol., 11(4):246-57, 1984.

Oohashi, Y.; Koshino, T. \& Oohashi, Y. Clinical features and classification of bipartite or tripartite patella. Knee Surg. Sports Traumatol. Arthrosc., 18(11):1465-9, 2010.

Paas, H. R. Zur Frage der Patella partita und ihrer Entstehung. Dtsch. Z. Chir., 230(3-5):261-77, 1931.

Saupe, E. Beitrag zur Patella bipartita. Fortschr. Röntgenstr., 28:37$41,1921$.

Siemens, W. Patella partita. Dtsch. Z. Chir., 233(9-10):727-55, 1931.

Snoeckx, A.; Vanhoenacker, F. M.; Gielen, J. L.; Van Dyck, P. \& Parizel, P. M. Magnetic resonance imaging of variants of the knee. Singapore Med. J., 49(9):734-44, 2008.
Stucke, K. Die patella partita in ihren beziehungen zum unfall and zer wehrdienst-beschadignung. Monatsschr. Unfallheilk., 53:238, 1950.

Todd, T. W. \& McCally, W. C. Defects of the patellar border. Ann. Surg., 74(6):775-82, 1921.

Weaver, J. K. Bipartite patellae as a cause of disability in the athlete. Am. J. Sports Med., 5(4):137-43, 1977.

\author{
Correspondence to: \\ Dr. Ali Eraslan \\ Sports Medicine Department \\ Antalya Education and Research Hospital \\ Varlık Mahallesi \\ Kazım Karabekir Caddesi \\ 07100 Antalya \\ TURKEY
}

Phone: +90242 2494400

Fax: +902422494462

Email: eraslanali@yahoo.com

Received:25-12-2014

Accepted:01-06-2015 